\title{
Use of complementary and alternative medicine by patients with dermatological disorders in western part of India: a prospective study
}

\author{
Nayana J. Gohil* \\ Department of Pharmacology, Shantabaa Medical College and General Hospital, Amreli, Gujarat, India
}

\author{
Received: 04 April 2020 \\ Revised: 03 August 2020 \\ Accepted: 05 August 2020 \\ *Correspondence: \\ Dr. Nayana J. Gohil, \\ Email: drpiyushpujara@gmail.com
}

Copyright: $(\odot$ the author(s), publisher and licensee Medip Academy. This is an open-access article distributed under the terms of the Creative Commons Attribution Non-Commercial License, which permits unrestricted non-commercial use, distribution, and reproduction in any medium, provided the original work is properly cited.

\begin{abstract}
Background: This study was aimed in assessing the prevalence and pattern of CAM in patients with dermatological disorders.

Methods: This cross sectional study was carried out at outpatient department of Dermatology at tertiary care teaching hospital. Data was collected with help of questionnaire which contained sociodemographic details and details of use of CAM if any by the attending patients. Data was analysed for sociodemographic and clinical character, pattern of use of CAM, source of information and reasons for using CAM.

Results: Mean age of participants was $29.29 \pm 20.25$ (Mean \pm SD) years and $102(46.54 \%)$ users were women. Highly educated patients $(49.25 \%)$ were the most frequently CAM users. Below 20 years $(57.84 \%)$ youngsters were the frequent CAM users. About $45.19 \%$ patients were belonging to rural area of community. Acne vulgaris was the commonest condition for CAM use. Folk medicines (70.73\%) were the most frequent used CAM. Advised by friends/relatives was the commonest source of information. About $80.49 \%$ patients had not informed to their physician about the use of CAM. None of the patients had knowledge of adverse effect of CAM.

Conclusions: Use of CAM is very common in dermatological disorders, youngsters and literate were the most common CAM users. Combined administration of herbs with prescription drugs may increase or decrease the pharmacological or toxicological effects of either compound.
\end{abstract}

Keywords: Acne vulgaris, CAM, Dermatological disorders

\section{INTRODUCTION}

The National Centre for Complementary and Alternative Medicines (NCCAM) defines CAM as a group of diverse medical and health systems, practices and products that are not presently considered to a part of conventional medicine. ${ }^{1}$ Complementary medicine is together with conventional medicine while alternative medicine is use in place of conventional medicine. ${ }^{1}$ Utilizaton of CAM is a universal phenomenon both in developing countries and developed countries like USA.,3 Ayurveda the oldest system of medicine is the commonly prescribed form of CAM in India fulfilling the medical need of $80 \%$ of the population. ${ }^{4}$
Studies have documented that about half of the population of many industrialized countries used traditional, complementary and alternative medicine and proportion is as high as $80 \%$ in many developing countries..$^{5}$ It is being widely used in India and about 2860 hospitals provide CAM services. ${ }^{6,7}$ Herbal medicines are increasingly becoming popular as alternative medicine and estimated one third adult population from developing countries and $80 \%$ from developed countries are using herbs as an alternative medicines often in combination with allopathic drugs which may lead to herb drug interaction by affecting pharmacokinetic and pharmacodynamic properties. ${ }^{8}$ 
Estimation of CAM use among adult with dermatological disease in the United States have varies from 50\% to $60 \% .^{9-11}$ Previous studies have revealed that the use of CAM is prevalent among patients with dermatologic disease, the frequency of CAM use being reported as between $21 \%$ to $49.69 \%$ depending on the country. ${ }^{12-17}$

Limited information about utilization pattern of CAM in dermatological disorders is available in India. Hence this study was planned with the aim of assessing the prevalence and pattern of the utilization of CAM in Out Patient Department of Dermatology at a tertiary care teaching hospital in Western part of India in Gujarat state.

\section{METHODS}

This was a questionnaire based cross sectional descriptive study. The study was carried out in Out Patient Department of dermatology at C. U. Shah Medical College and hospital in Surendranagar city of Gujarat state in India. The C. U. Shah hospital is a teaching hospital in Surendranagar catering to health needs of people in villages in Zalawad province as well as the Surendranagar city. The study was approved by the Institutional Ethics Committee. The study period was August 2010 to October 2010 (3 months). Patients of both sex and all age groups attending outpatient department of dermatology during study period were invited to participate. All the patients were informed about the study and its aim. Those patients who were willing to participate and consented for the study were included. A questionnaire to assess the prevalence and pattern of use of CAM was developed and validated by considering previous study. ${ }^{18}$ The questionnaire was pretested by pilot study in 20 patients. Modifications were made on the based on the responses and observations of the patients.

Questionnaire was filled in either by participants themselves or by investigator by asking questions to the literate patients and parents or guardians in case of children. Questionnaire included information regarding sociodemographic data, present clinical condition, allopathic medicines used and details of usage of complementary and alternative medicine, source of information for CAM, the reason for the CAM use and participant's knowledge of adverse drug reactions likely to occur with CAM.

For usage of complementary and alternative medicine patients were specifically asked about different CAM therapies including herbal remedied from Ayurveda, homeopathy, folk remedies, acupuncture, chiropractic, megavitamins, prayer or spiritual healing, commercial diet, programs, relaxations, meditation, massage, naturopathy, yoga etc. If patients were using CAM then further questions regarding CAM were asked. Most of the allopathic drugs were prescribed by their brand names. The generic content of each formulation was obtained from commercial publications like Indian Drug Review (IDR). Information regarding herbal or any alternative medicine was obtained from commercial web site (www.nccam.gov). Information not available from this source was obtained from local medicine shops.

\section{Sample size calculation}

Sample size of 285 was derived using Rao soft sample size calculator considering prevalence of $25 \%$ at $95 \%$ confidence with $5 \%$ margin of error. ${ }^{10}$ Data were analysed by using Microsoft excel 2007.

\section{Statistical analysis}

The recorded data was compiled and entered in a spreadsheet computer program (Microsoft Excel 2007) and then exported to data editor page of SPSS version 15 (SPSS Inc., Chicago, Illinois, USA). For all tests, confidence level and level of significance were set at $95 \%$ and $5 \%$ respectively.

\section{RESULTS}

\section{Prevalence of usage of CAM}

Total 500 patients were included in the study. Out of 500 patients $205(41 \%)$ reported using CAM. 13 patients (6.34\%) being current CAM users. Out of 205 CAM users $102(46.15 \%)$ were female.

Table 1: Demographic characteristics of study population $(n=500)$.

\begin{tabular}{|lllll|}
\hline Variable & Number & CAM users & $\begin{array}{l}\text { Prevalence } \\
(\%)\end{array}$ \\
\hline Gender & Male & $279(55.8)$ & 103 & 36.91 \\
\hline Age (years) & Female & $221(44.2)$ & 102 & 46.15 \\
\hline & $<10$ & $45(9)$ & 11 & 24.44 \\
\hline & $11-20$ & $102(20.4)$ & 59 & 57.84 \\
\hline & $21-30$ & $111(22.2)$ & 57 & 51.35 \\
\hline & $31-40$ & $79(15.8)$ & 27 & 34.17 \\
\hline & $41-50$ & $67(13.4)$ & 17 & 25.37 \\
\hline & $51-60$ & $57(11.4)$ & 20 & 35.08 \\
\hline
\end{tabular}




\begin{tabular}{|c|c|c|c|c|}
\hline Variable & & $\begin{array}{l}\text { Number } \\
(\%)\end{array}$ & CAM users & $\begin{array}{l}\text { Prevalence } \\
(\%)\end{array}$ \\
\hline \multirow[t]{5}{*}{ Religion } & Hindu & $455(91)$ & 184 & 40.43 \\
\hline & Muslim & $35(7)$ & 16 & 45.71 \\
\hline & Jain & $10(2)$ & 5 & 50 \\
\hline & Christian & $0(0)$ & 0 & 0 \\
\hline & Others & $0(0)$ & 0 & 0 \\
\hline \multirow[t]{3}{*}{ Monthly family income } & $<5000$ & $345(69)$ & 138 & 40 \\
\hline & $5000-10000$ & $116(23.2)$ & 46 & 39.65 \\
\hline & $>10000$ & $39(7.8)$ & 21 & 53.84 \\
\hline \multirow[t]{4}{*}{ Education } & Illiterate & $69(13.8)$ & 27 & 39.13 \\
\hline & Can read and write & $181(18.2)$ & 69 & 38.12 \\
\hline & Up to school level & $183(36.6)$ & 76 & 41.53 \\
\hline & Graduates & $67(13.4)$ & 33 & 49.25 \\
\hline \multirow[t]{3}{*}{ Background } & Rural & $208(41.6)$ & 94 & 45.19 \\
\hline & Semi urban & $104(20.8)$ & 35 & 33.65 \\
\hline & Urban & $188(37.6)$ & 76 & 40.42 \\
\hline
\end{tabular}

Mean age of participants was 29.29 $\pm 20.25($ Mean \pm SD) years. Educated patients reported most frequent use of CAM with $49 \%$ while lower education, patients can read and write reported lower use at 38\%. Majority of CAM users were from rural area $(45.19 \%)$. About $57.84 \%$ of patients aged between 11 to 20 years used most frequently.

Table 2: Common condition for which CAM was used $(n=205)$.

\begin{tabular}{|lll|}
\hline Characteristics & Total number & Prevalence (\%) \\
\hline Acne vulgaris & 76 & 37.07 \\
\hline Eczema & 23 & 11.22 \\
\hline Scabies & 16 & 7.80 \\
\hline Lichen simplex & 6 & 2.93 \\
\hline Dematitis & 16 & 7.80 \\
\hline Urticaria & 21 & 10.24 \\
\hline Alopecia & 1 & 0.49 \\
\hline Hair fall & 4 & 1.95 \\
\hline Tinea infection & 4 & 1.95 \\
\hline Pityriasis infection & 4 & 1.95 \\
\hline Psoriasis & 15 & 7.32 \\
\hline Prurigo & 2 & 0.98 \\
\hline Melasma & 1 & 0.49 \\
\hline Tanning & 4 & 1.95 \\
\hline Sun burn & 2 & 0.98 \\
\hline Hyper pigmentation & 9 & 4.39 \\
\hline Itching & 1 & 0.49 \\
\hline
\end{tabular}

Majority of CAM users were from rural area (45.19). About $57.84 \%$ of patients were included in age group of 11 to 20 years. (Table 1). Usage of CAM was most frequent in acne vulgaris $(37.07 \%)$ followed by eczema $11.22 \%$ (Table 2).

Friends/relatives (48.26\%) were the most information source followed by self experience $(35.12 \%)$. Only $6.83 \%$ of patients had used CAM on recommendation by qualified physician. About $66.83 \%$ of patients stated that they have used CAM because of cost benefit and $77.07 \%$ patients reported no change in condition. $1.95 \%$ of patients experiencing adverse effect after using CAM.

Table 3: Characteristics of the individuals related to their use of CAM methods $(n=205)$.

\begin{tabular}{|c|c|c|}
\hline Characteristics & Number & Percent \\
\hline \multicolumn{3}{|l|}{ Which CAM is used } \\
\hline Ayurveda & 38 & 18.53 \\
\hline Homeopathy & 3 & 1.46 \\
\hline Unani & 0 & 0.00 \\
\hline Folk medicine & 145 & 70.73 \\
\hline Others & 19 & 9.25 \\
\hline \multicolumn{3}{|c|}{ Source of information about CAM usage } \\
\hline Qualified practitioners & 14 & 6.83 \\
\hline Advice by friends/relatives & 99 & 48.29 \\
\hline TV/internet/media & 20 & 9.76 \\
\hline Self medication & 72 & 35.12 \\
\hline \multicolumn{3}{|c|}{ Information to their doctor about CAM usage } \\
\hline Yes & 40 & 19.51 \\
\hline No & 165 & 80.49 \\
\hline \multicolumn{3}{|c|}{ CAM used associated with cost benefit } \\
\hline Yes & 137 & 66.83 \\
\hline No & 68 & 33.17 \\
\hline \multicolumn{3}{|l|}{ Result experienced } \\
\hline Beneficial & 43 & 20.89 \\
\hline Harmful & 4 & 1.95 \\
\hline No change & 158 & 77.07 \\
\hline \multicolumn{3}{|c|}{ Knowledge about side effect of CAM } \\
\hline Yes & 0 & 0.00 \\
\hline No & 205 & 100 \\
\hline
\end{tabular}

About $80.49 \%$ of the patients had not disclosed to their physician about the use of CAM. None of the patients had knowledge about side effects and possible drug interaction of CAM with prescription medicines. 
Looking to the types of CAM used, majority (70.73\%) were using folk medicines followed by Ayurvedic medicines (18.53\%) (Table 3).

Table 4: Distribution of CAM used orally $(n=15)$.

\begin{tabular}{|c|c|c|}
\hline Medicine & Disease & $\begin{array}{l}\text { No. of } \\
\text { patients }(\%)\end{array}$ \\
\hline \multirow{3}{*}{ Homeopathic tablet } & Eczema & $1(6.6)$ \\
\hline & Acne vulgaris & $2(13.3)$ \\
\hline & Total & $3(20)$ \\
\hline Garlic & Hypertension & $2(13.33)$ \\
\hline $\begin{array}{l}\text { Gandhak rasayan } \\
\text { churna }\end{array}$ & Eczema & $3(20)$ \\
\hline \multirow{3}{*}{$\begin{array}{l}\text { Mahamanjishthadi } \\
\text { kwath }\end{array}$} & Acne vulgaris & $3(20)$ \\
\hline & Psoriasis & $2(13.33)$ \\
\hline & Total & $5(33.33)$ \\
\hline Tab Arogyavardhini & Acne vulgaris & $2(13.33)$ \\
\hline
\end{tabular}

Table 5: Distribution of CAM use topically by using folk medicines $(n=145)$.

\begin{tabular}{|ll|}
\hline Methods used & Number $(\%)$ \\
\hline Bengalgram flour & $10(4.88)$ \\
\hline Glycerine & $2(0.98)$ \\
\hline Shankhjeeru & $5(2.44)$ \\
\hline Kokam ghee & $1(0.49)$ \\
\hline Multani sand & $10(4.88)$ \\
\hline Olive oil & $2(0.98)$ \\
\hline Ghee & $1(0.49)$ \\
\hline Rose water & $2(0.98)$ \\
\hline Ponds cream & $2(0.98)$ \\
\hline Butter & $1(0.49)$ \\
\hline Aloe Vera gel & $27(13.17)$ \\
\hline Veseline & $20(9.76)$ \\
\hline Coconut oil & $11(5.37)$ \\
\hline Honey + lemon juice & $6(2.93)$ \\
\hline Sandalwood powder & $7(3.41)$ \\
\hline Ash (bhasm) & $2(0.98)$ \\
\hline Badam oil & $1(0.49)$ \\
\hline Telcum powder & $3(1.46)$ \\
\hline Maisurdal powder & $2(0.98)$ \\
\hline Fudina (mint) & $3(1.46)$ \\
\hline Neem leaves water bath & $11(5.37)$ \\
\hline Castor oil & $1(0.49)$ \\
\hline Neem leaves & $6(2.95)$ \\
\hline Nutmeg & $2(0.98)$ \\
\hline Til oil & $4(1.95)$ \\
\hline Turmeric & $2(0.98)$ \\
\hline
\end{tabular}

Aloe Vera gel $(13.17 \%)$ was the most frequently used topical folk medicine followed by Vaseline (9.76\%), neem leaves water $(5.37 \%)$, coconut oil $(5.37 \%)$ and multani sand $(4.88 \%)$ (Table 5$)$.

Among the orally used medicine by 15 patients mahamanjishthadi kwath (33.33\%) followed by homeopathic tablet (20\%), gandhak rasayan churna (20\%) and garlic $(13.33 \%)$ were used. Other types of CAM reported were itch guard cream $(3.41 \%)$ and Johnson's baby cream $(1.46 \%)$ (Table 4$)$.

Table 6: Distribution of CAM use topically by using Ayurvedic medicines ( $\mathrm{n}=38$ ).

\begin{tabular}{|ll|}
\hline Methods used & Number $(\%)$ \\
\hline Neem soap bath & $6(2.22)$ \\
\hline Maha bhrungraj hair oil & $2(0.98)$ \\
\hline Kumkumadi oil & $5(2.44)$ \\
\hline Patanjali aloe vera gel & $4(1.95)$ \\
\hline Herbal facepack & $2(0.98)$ \\
\hline Raktachandan powder & $1(0.49)$ \\
\hline Natural golden face pack & $1(0.49)$ \\
\hline Ruturaj hair oil & $1(0.49)$ \\
\hline Vico turmeric cream & $2(0.98)$ \\
\hline Dabar amla hair oil & $1(0.49)$ \\
\hline Lotus cream & $1(0.49)$ \\
\hline Navratna hair oil & $1(0.49)$ \\
\hline
\end{tabular}

Neem soap was the most frequently used ayurvedic remedy $(2.92 \%)$ followed by kumkumadi oil $(2.44 \%)$ (Table 6).

Table 7: Distribution of CAM use topically by using other medicines $(\mathrm{N}=19)$.

\begin{tabular}{|ll|}
\hline Methods used & Number $(\%)$ \\
\hline Itch guard cream & $7(3.41)$ \\
\hline Himalaya cream & $2(0.98)$ \\
\hline Crack cream & $1(0.49)$ \\
\hline Sun screen lotion & $1(0.49)$ \\
\hline Orange pill & $2(0.98)$ \\
\hline Dettol soap & $2(0.98)$ \\
\hline Johnson's baby cream & $3(1.46)$ \\
\hline Himalaya face wash & $1(0.49)$ \\
\hline
\end{tabular}

Itch guard cream (3.41) was the most frequently used other type of medicine followed by Johnson's baby cream (1.46).

\section{DISCUSSION}

Many studies carried out in dermatological disorders in USA, England, Germany, Taiwan, Turkey and Switzerland. Limited data for dermatological disorders are available in India. Estimation of CAM use among adults with dermatological disease in the United States varies from $50 \%$ to $60 \% .{ }^{9-11}$ In various studies it was stated that the prevalence of CAM methods in dermatology patients was $49.9 \%$ in USA; $26.5 \%$ in Germany; $35 \%$ in Switzerland; $41 \%$ in Taiwan; 35-69\% in UK; and $21 \%$ in Turkey. ${ }^{12-17}$ In our study about $41 \%$ patients had used CAM which is accordance with report from Taiwan. ${ }^{15}$ The low prevalence is due to inclusion of 
all types of dermatological disorders acute as well as chronic.

Chen et al reported that use of CAM methods was recommended to the majority of individuals by friends and relatives followed by media and doctors. ${ }^{15}$ Similarly in the present study majority of patients $(48.29 \%)$ had used CAM as advised by friends and family members while $35 \%$ of patients had used CAM as self-medication. Only $6.38 \%$ of the patients were using CAM on advice of qualified practitioners. Eser at al reported that to want to try was common reason for most of the individuals to use CAM and it was natural and less adverse effect, less expensive. ${ }^{17}$ Similarly another study, also reported that people just wanted to optimize therapy by using CAM. ${ }^{12}$ Our study is in accordance with Esere et al, in our study majority of $(66.83 \%)$ patients had stated that CAM is less expensive only $33.17 \%$ patients had reported that CAM is natural, safe and having less adverse effect than allopathic medicine. ${ }^{17}$

Study conducted by Smith et al in USA, oral therapy remain the common route of administration. ${ }^{12}$ In the present study it was found that majority of CAM methods used by patients were applied topically. Out of 51 types of CAM remedies, 46 types were topically applied. However in chronic ailments CAM remedies were used systemically $(7.3 \%)$. Our study is in contrast with Smith et al. ${ }^{12}$ Aloe Vera gel (13.5\%), neem leaves (11.22\%), Vaseline $(9.76 \%)$ being the most frequently topically used CAM remedies. Mahamanjishthadi kwath, gandhak rasayanchurn and garlic (for hypertension) were the orally used CAM remedies. Mahamanjishthadi kwath was the most frequently (33.33\%) orally used herb.

Schafor et al and Ernst et al reported that a higher of CAM by patients with pruritis. ${ }^{13,16}$ In our study it was found that acne vulgaris $(37.07 \%)$ remain the main reason for usage of CAM.

Eser et al reported that the most common reason for most of the individuals to CAM were is natural, less adverse effects and less expensive. ${ }^{17}$ In our study majority $(70.73 \%)$ of patients had used folk remedies as CAM. Ayurvedic medicines were used by only $18.53 \%$ of the patients as the cost of therapy for Ayurveda is in general less than allopathy but more than house hold remedies which could be the reason for high usage of household or folk remedies. These findings are in agreement with Eser et al. ${ }^{17}$

Many studies reported that apart from herbs acupuncture, aroma therapy, homeopathy, and mega vitamins were the popularly used types of CAM. ${ }^{12-17}$ In our study $1.5 \%$ patients had used homeopathy and none of the patients had used yoga to treat their dermatological ailments. This could be due to lack of awareness about these therapies in the region where this study was carried out. Moreover use of CAM therapies varies from country to country depending upon their cultural beliefs regarding indigenous medicines being prevalent e.g. in China traditional Chinese medicine such as herbal medicine, acupuncture, acupressure, Qi gong and t'ai chi chu'an are widely used while in Japan kampong and acupuncture are commonly used CAM therapy. ${ }^{18}$

In a previous study $56.5 \%$ of the patients had stated that there was no change in complaints and $75.8 \%$ had never disclosed their CAM use with their doctors. ${ }^{17}$ Majority of the respondents $(77.07 \%)$ in our study also reported no change in complaints. Eser et al reported that $75.8 \%$ of the individuals who used CAM did not share the use of CAM methods with their physician. Similarly in our study a higher proportion of CAM users $(80.49 \%)$ did not reveal their CAM use to their doctors. ${ }^{17}$

Smith et al reported that use of CAM therapy is more common among women than men as in our study also $44.54 \%$ CAM users were women. ${ }^{12}$ Schafer et al reported that the group with higher education used CAM more. ${ }^{13}$ Collins also reported that higher education is positively associated with CAM use. ${ }^{9}$ Similar findings were determined in study done in United States, Taiwan, Turkey and UK in dermatological ailments. ${ }^{15,17,18}$ Similarly in our study usage of CAM was highest $(49.25 \%)$ in the patients who has completed their graduation.

Eser et al reported that to want to try was common reasons for most of the individuals to use CAM and it was less expensive. ${ }^{17}$ Smith et al reported that people just wanted to optimize therapy by using CAM. ${ }^{12}$ Similarly in our study $33.17 \%$ of the patients had stated that CAM therapy was less expensive, $11.83 \%$ of the patients stated that they wanted to try whether CAM is working or not. While majority $(55 \%)$ of the patients believed that CAM therapy does not cause any adverse effect because it is natural and safe. In the previous study it was reported that use of CAM is high amongst individual in 30-50 years of age group..$^{15,19,20}$ In contrast in our study majority of CAM users were in 11-20 years of age group. This can be explained by the use of CAM method at a high percentage (37.07\%) for the treatment of Acne vulgaris, a common problem experienced by young people. Chen et al reported that the greatest prevalence of all types of CAM use by young people and young people can increase the prevalence of use of CAM methods in future. ${ }^{15}$ Smith et al reported that the use of CAM therapy was more common among women men in dermatological disorders. ${ }^{12}$ Jensen and Eser et al reported that there were no significant difference between male and female in the use of CAM method. ${ }^{17,20}$ Our findings are in accordance with Smith et al, in our study CAM therapies remain more frequently used among women $(44.54 \%)$ than men $(36.91 \%){ }^{12}$

\section{CONCLUSION}

Use of CAM is quite prevalent in patients suffering from dermatological disorders and percentage of prevalence rate is $41 \%$. Folk remedies are most frequently used. Women, young people and literate are more likely to use CAM. Higher income earners are frequently associated 
with CAM use. Acne vulgaris remain the dermatological condition for using CAM. The fact that most users do not inform their doctors about use of CAM needs attention. The treating doctors should be positively ask the history of CAM to patients so as to avoid unwanted drug inter actions resulting from them.

Funding: No funding sources

Conflict of interest: None declared

Ethical approval: The study was approved by the Institutional Ethics Committee

\section{REFERENCES}

1. What Is Complementary and Alternative Medicine? Available at: nccih.nih.gov/sites/nccam.nih.gov/files/ D347_05-25-2012pdf. Accessed on 15 March 2016.

2. Kinsel JF, Straus SE. Complementary and alternative therapeutics. Rigorous research is need to support chains. Annu Rov Pharmacol Toxicol. 2003:43;46384.

3. Sharma R, Kapoor B, Verma U. Drug utilization pattern during pregnancy in, northern India. Indian $\mathbf{J}$ Med Sci. 2006;60;277-88.

4. Goktay NJ, Bhatta HA, Dalvi SS, Kshrisagar NA. The use and safety of nonallopathic Indian medicines. Drug Sal. 2002;25:1005-19.

5. Bodeker G, Kronenberg F. A public health agenda for traditional, complementary, and alternative medicine. Am J Public Health. 2002;92(10):1582-91.

6. Shafiq N, Gupta M, Kumari S, Pandhi P. Prevalence and pattern of use of complementary and alternative medicines (CAM) in hypertensive patients of a tertiary care center in India. Int $\mathrm{J}$ Clin Pharmacol Ther. 2003;41(7):294-8.

7. Kumar D, Chandel JK, Bhardwaj AK, Raina SK, Sharma YK. Rationale of integration of complementary and alternative medicine (CAM) health facilities in non communicable disease (NCDS) surveillance, North India. J Community Med Health Educ. 2012;2:147-8.

8. Hu Z, Yang X, Ho PC, Chan SY, Heng PW, Chan E, et al. Herb- drug interactions: a literature review. Drugs. 2005;65(9):1239-82.

9. Collins SC, Dufresne RG Jr. Dietary supplements in the setting of Mohs Surgery. Dermatol Surg. 2002;28:447-52.

10. Simpson EL, Basco M, Hanifin J. A cross sectional survey of complementary and alternative medicine use in patients with atopic dermatitis. Am J Contact Dermatit. 2003:14:144-7.

11. Fleischer JA, Feldman SR, Rapp SR, Reboussin DM, Exum ML, Clark AR. Alternative therapies commonly used within a population of patients with psoriasis. Cutis. 1996;58(3):216-20.

12. Smith N, Shin DB, Brauer JA, Mao J, Gelfand JM. Use of complementary and alternative medicine among adults with skin disease. Results from a national survey. J Am Acad Dermatol. 2009:60(3):419-2.

13. Schafer T, Riehle A, Wichman HE, Ring J. Alternative medicine in allergies prevalence, patterns of use, and costs. Allergy. 2002;57(8):694-700.

14. Berg M, Ametz B. Characteristics of users and non users of alternative medicine in dermatological patients attending a university hospital clinic: a short report. Journal Altern Copliment Med. 1998;4(3)2779

15. Chen YF, Chang JS. Complementary and alternative medicine, use among patients attending a hospital dermatology clinic in Taiwan. Int $\mathbf{J}$ Dermatol. 2003;42:616-21.

16. Ernst E. Prevalence of use of complementary and alternative medicine: a systemic review. Bull World Health Organ. 2000;78(2):252-7.

17. Eşer I, Khorshid L, Demir Y, Denat Y. The use of complementary and alternative medicine in dermatology patients in western Turkey. J Hum Sci. 2010;7(1):384-400.

18. Wootton JC, Sparber A. Surveys of complementary and alternative medicines: part I. General trends and demographic groups. J Altern Complement Med. 2001;7:195-208.

19. Eisenberh DM, Devis RB, Ettner SI, Appel S, Wilkey S, Van Rompay $M$, et al. Trends in alternative medicine use in United States, 1990-1997: results of flow-up national survey. JAMA. 1998;280:1569-75.

20. Jansen P. Alternative therapy for atopic dermatitis and psoriasis; patient reported motivation, information source and effect. Acta Derm Venereol. 1990;70(5):425-8.

Cite this article as: Gohil NJ. Use of

complementary and alternative medicine by patients with dermatological disorders in western part of India: a prospective study. Int J Basic Clin Pharmacol 2020;9:1351-6. 